\title{
Numerical Simulation of Ventilation for Main Transformer Room of In- door Substations
}

\author{
Yang Huijuan ${ }^{1}$, Yu Tingfang ${ }^{1, *}, X^{*}$ Rui $^{2}$ and Peng Chunhua ${ }^{3}$ \\ ${ }^{I}$ School of Mechanical and Electronic Engineering, Nanchang University, Nanchang, China \\ ${ }^{2}$ Jiangxi Electric Power Testing \& Research Institute, Nanchang, China \\ ${ }^{3}$ School of Electrical \& Electronic Engineering, East China Jiaotong University, Nanchang, China
}

\begin{abstract}
Main Transformer Room of an indoor substation in Nanchang City was studied. By designing schemes with different air inlet and outlet positions, six ventilation schemes were proposed. Fluent software was used to establish reasonable mathematical and physical models for the six ventilation schemes of this main transformer room, and CFD numerical simulation was performed. According to the numerical simulation results, the indoor air distributions for the different schemes were compared by analyzing the velocity and temperature fields. The advantages and disadvantages of the various schemes were analyzed, and good schemes for air distribution for ventilation were obtained. The simulation results are of guiding significance to practical engineering and can provide a reference for the design of ventilation schemes of indoor transformer rooms.
\end{abstract}

Keywords: Numerical simulation, Ventilation and cooling, Transformer room, Indoor ventilation.

\section{INTRODUCTION}

With the rapid development of China's economy, many cities have suffered from a short supply of electricity, thereby causing many transformers to constantly transfer to cities. Due to limited areas and the need to consider the effect of noise on surroundings, newly built substations in urban areas or inner suburbs are often configured completely indoor [1, 2]. Nowadays, indoor substations have been popular in small and medium-sized cities. Transformers have a complex structure and high requirements for operating environments. How to discharge the large quantities of heat generated during transformer operation through ventilation in order to ensure safe and stable transformer operation, is one of the major tasks of substation design [3, 4].

The main transformer rooms of indoor substations are characterized by large sizes and considerable heat dissipation. After the incoming air is heated, the density of the air will decrease, thus generating bottom-up natural convection airflow due to temperature difference. Therefore, transformer rooms generally use down-supply up-return ventilation to cause the direction of the inlet and outlet airflow to be consistent with that of natural convection, thereby producing a longitudinal temperature gradient [5]. However, the design specifications for the ventilation and air conditioning of indoor substations [6] require that ventilation in transformer rooms should ensure that the temperature in areas for human

\footnotetext{
*Address correspondence to this author at the School of Mechanical and electronic Engineering, Nanchang University, Jiangxi, 330031, P.R. China; Tel: 18070091102; E-mail:wtu_tingfy@163.com
}

activities should not exceed $40^{\circ} \mathrm{C}$ and indoor temperature should not exceed $45^{\circ} \mathrm{C}$. Currently, studies on the ventilation design of transformer rooms of indoor substations have focused on two aspects: to select and arrange ventilation equipment by calculating heat dissipation and ventilation as required by national and industry specifications [3] and to design different schemes using computational fluid dynamics (CFD) methods, simulate velocity and temperature fields, and obtain the best scheme by analyzing the results [7-13].

Literature $[7,8]$ used CFD to study natural ventilation in buildings. Literature [9] used CFD methods to study indoor ventilation in industrial plants with waste heat. Literature [10-13] used CFD to analyze the design of ventilation schemes for underground and semi-underground substations. With the successful application of CFD in various fields, it will become a trend to use CFD to numerically simulate the air distribution for the ventilation of indoor substations in order to optimize the design of substations.

This paper studied Main Transformer Room of an indoor substation in Nanchang City. By designing schemes with different air inlet and outlet positions, six ventilation schemes were proposed. CFD methods were used to numerically simulate the six schemes. The indoor air distributions for the schemes were compared by analyzing the velocity and temperature fields according to the numerical simulation results. The advantages and disadvantages of the schemes were analyzed, and good schemes for air distribution for ventilation were obtained, providing a reference for engineering design. 
Table 1. Original data for the transformer room.

\begin{tabular}{|c|c|c|c|c|}
\hline No. & Item & Symbol & Unit & Value \\
\hline 1 & No-load Loss of Main Transformer & $Q_{k z}$ & $\mathrm{~kW}$ & 27.57 \\
\hline 2 & Load Loss of Main Transformer & $Q_{f z}$ & $\mathrm{~kW}$ & 154.69 \\
\hline 3 & Total Heat & $Q$ & $\mathrm{~kW}$ & 182.26 \\
\hline 4 & Inlet Air Temperature & $T_{0}$ & K & 306 \\
\hline 5 & Operating Air Temperature (set) & $T_{n}$ & $\mathrm{~K}$ & 313 \\
\hline
\end{tabular}

Table 2. Results calculated for forced ventilation.

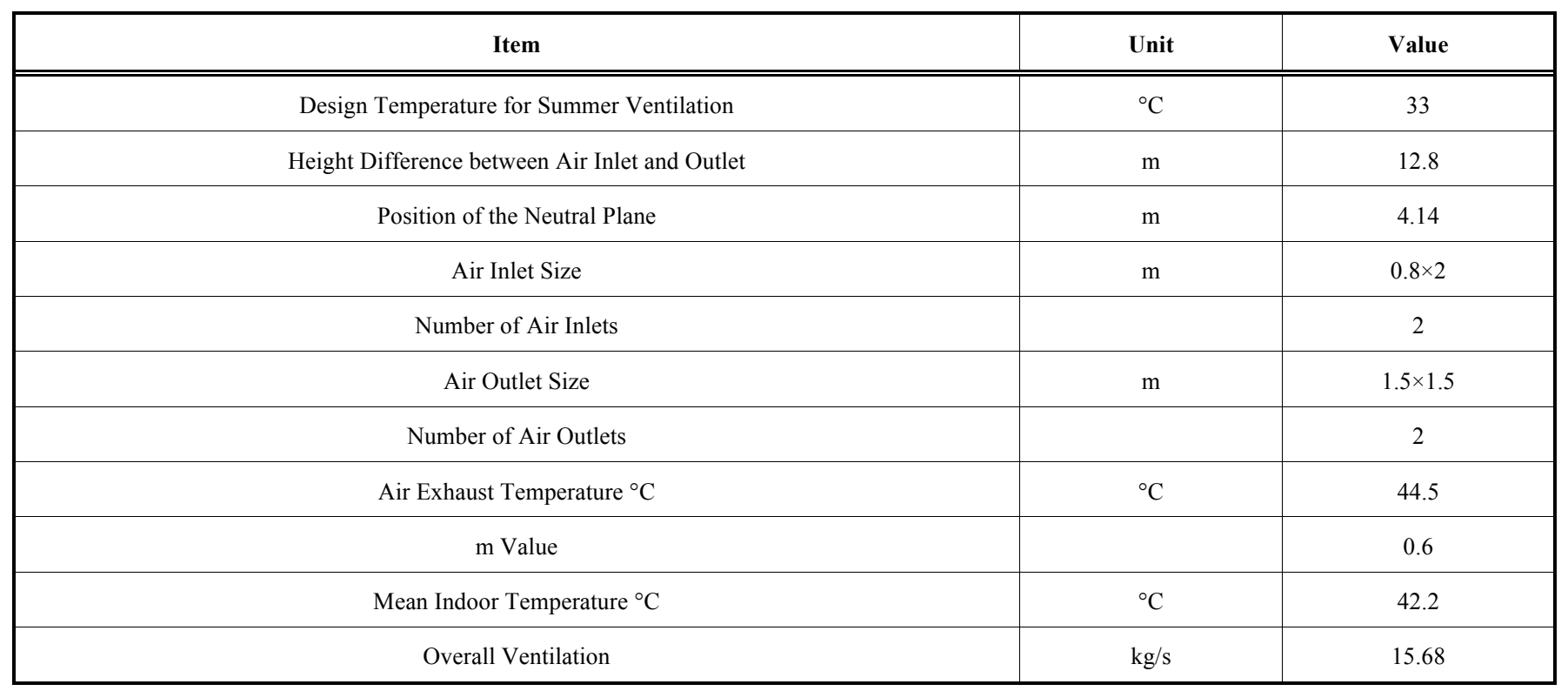

\section{PHYSICAL MODEL}

\subsection{Simplification of the Physical Model}

Two air inlets and two air outlets were designed for the transformer room. The transformer room was $9.8 \mathrm{~m}$ long, 8 $\mathrm{m}$ wide, and $13.8 \mathrm{~m}$ high. Table 1 gives the original data for the transformer room, showing that the full power load of the heat sources of the main transformer is $182.26 \mathrm{~kW}$. At an ambient temperature of $33^{\circ} \mathrm{C}$ in summer, it is difficult to rely on buoyancy-driven natural ventilation alone to remove indoor waste heat, and forced ventilation is often used. Table 2 shows the results calculated for forced ventilation. The $\mathrm{x}$ coordinate was the length direction, the y-coordinate was the width direction, and the $\mathrm{z}$-coordinate was the height direction. The two air inlets were $0.8 \mathrm{~m}$ wide and $2 \mathrm{~m}$ high, and the two air outlets were $1.5 \mathrm{~m} \times 1.5 \mathrm{~m}$. Due to the complex external dimensions of transformers, it is difficult to simulate their structure when establishing physical models, and transformers are often simplified. When establishing the model, this paper used a cuboid that was $5 \mathrm{~m}$ long, $4 \mathrm{~m}$ wide, and 3 $\mathrm{m}$ high.

\subsection{Physical Models for the Various Schemes for Ventila- tion}

Fig. (1) shows the six air inlet and outlet arrangement schemes for the main transformer room, where (a) (c) are three air distribution schemes for ventilation with the same air inlet position (on the side of the main transformer) and different air outlet positions (in the front, middle, and rear of the top), and (d) (f) are three air distribution schemes for ventilation with the same air outlet position (in the middle of the top) and different air inlet positions (on the two sides, in the front and rear).

\section{MATHEMATICAL MODEL AND THE TREAT- MENT OF BOUNDARY CONDITIONS}

\subsection{Mathematical Model}

This paper studied three-dimensional steady-state incompressible turbulent flow [14]. The finite volume method was used to establish discrete equations. The second order upwind scheme, the standard $\mathrm{k}-\varepsilon$ model [15], the segregated 


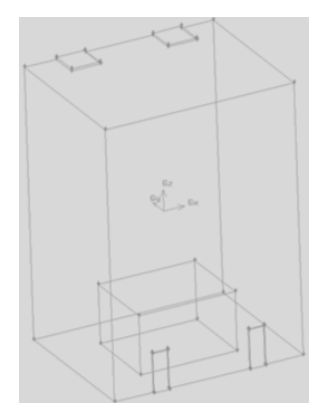

(a) Scheme a

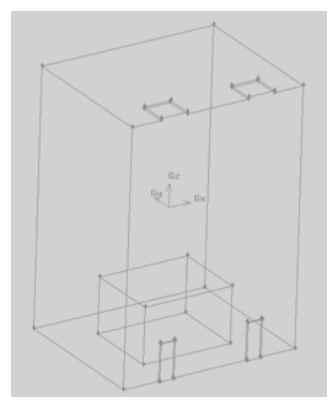

(c) Scheme c

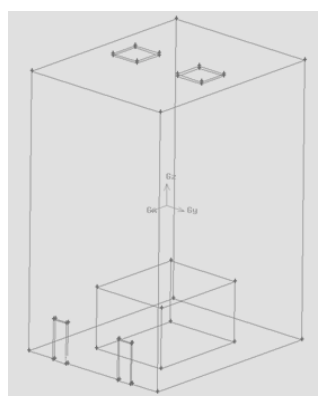

(e) Scheme e

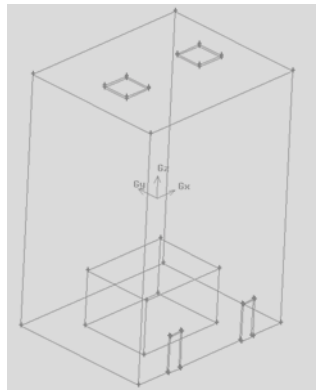

(b) Scheme b

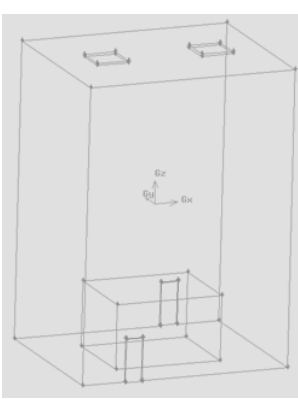

(d) Scheme d

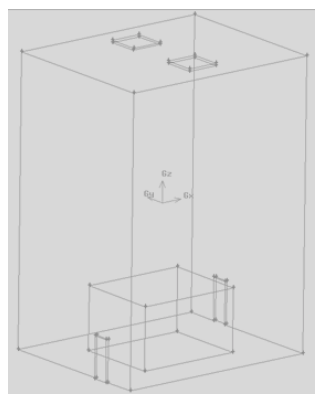

(f) Scheme f

Fig. (1). Six air inlet and outlet arrangement schemes for ventilation of the main transformer room.

Table 3. Fluent calculation parameters.

\begin{tabular}{|c|c|c|c|}
\hline Turbulence Model & Wall Flow Treatment & Buoyancy Force & Pressure-Velocity Coupling \\
\hline \hline Standard k- $\varepsilon$ & Standard Wall Function & Boussinesq \\
\hline \multicolumn{2}{|c|}{ Spatial Discretization } \\
\hline Pressure Term & $k$ & $\varepsilon$ & Energy Equation \\
\hline Body Force Weighted & Second Order Upwind & Second Order Upwind & Second Order Upwind \\
\hline Spatial Discretization & \multicolumn{2}{|c|}{ Boundary Conditions } \\
\hline Momentum Equation & Air Inlet & Air Outlet & Other Boundary \\
\hline Second Order Upwind & Velocity-inlet & Outflow & Wall \\
\hline
\end{tabular}

solver and the SIMPLEC algorithm were used. The calculation parameters were set as shown in Table $\mathbf{3}$. Considering the effect of temperature on density, the buoyancy force caused by temperature difference was approximated [16]. Basic control equations include continuity, momentum, and energy equations [17].

\section{1) Continuity equation}

According to Reynolds assumptions, flow at any instant at each point in the flow field obeys the basic equation for continuum flow:

$\partial \rho / \partial t+\partial(\rho u) / \partial x+\partial(\rho v) / \partial y+\partial(\rho w) / \partial z=0$ 
Table 4. The area-weighted averages of temperature in the sections in the height direction in the operating area (K).

\begin{tabular}{|c|c|c|c|c|c|c|}
\hline Height & Scheme a & Scheme b & Scheme c & Scheme d & Scheme e & Scheme f \\
\hline \hline $0.8 \mathrm{~m}$ & 316.09 & 316.96 & 313.28 & 314.57 & 316.36 & 313.31 \\
\hline $1.5 \mathrm{~m}$ & 316.18 & 316.91 & 314.08 & 314.68 & 316.37 & 313.31 \\
\hline $2 \mathrm{~m}$ & 317.07 & 317.64 & 314.52 & 315.66 & 317.52 & 313.76 \\
\hline
\end{tabular}

Where the second, third, and fourth terms are the divergence of mass flow density and can be written as vector symbols:

$\partial \rho / \partial t+\nabla(\rho U)=0$

The density of incompressible fluid is a constant, and the continuity equation is simplified to:

$\nabla(U)=0$

Where $\nabla$ is a differential operator, and $U$ is a velocity vector.

2) Differential energy equation

For an infinitesimal control volume in a flow field, the differential energy equation can be obtained using the continuity equation according to the first law of thermodynamics:

$\rho C_{V} \cdot(D T / D \tau)=\nabla(a \nabla T)+Q$

Where $Q$ is the heat generated per unit volume, $T$ is temperature, $C_{v}$ is constant volume heat capacity, $\tau$ is a time constant, $\rho$ is density, $\alpha$ is the thermal diffusion coefficient, and $D T / D \tau$ is an operator.

\section{3) Differential momentum equation}

For an infinitesimal control volume in a flow field, the differential momentum equation ( $N-S$ equation) can be obtained using the continuity equation according to the momentum conservation law:

$$
\rho \cdot(D T / D \tau)=F-\nabla P+\mu \nabla^{2} V
$$

Where $\mu$ is the dynamic viscosity coefficient, $P$ is pressure, $\rho . D T / D \tau$ is inertia force, $F$ is the buoyancy force caused by uneven density, $\nabla P$ is the total pressure gradient, and $\mu \nabla V^{2}$ is viscous force.

\subsection{Treatment of Boundary Conditions}

\subsubsection{Wall Boundary Conditions}

A fixed heat flux was set at the wall of the transformer, and the transformer's surface heat flux was $2,432 \mathrm{~W} / \mathrm{m}^{2}$. The heat flux on surrounding walls was zero. Velocity, $\mathrm{k}$, and $\varepsilon$ were all zero.

\subsubsection{Boundary Conditions for Air Inlets and Outlets}

The velocity inlet boundary condition was applied at the air inlets. According to ventilation requirements, the inlet velocity was set at $4 \mathrm{~m} / \mathrm{s}$. Simple air inlets were used to replace complex air inlets for modeling. During simulation, the original outflow characteristics of the air inlet would be altered, but the consistency between the mass, momentum, and buoyancy flux of inflow and reality could be ensured in order to ensure the consistency between indoor air distribution and actual air distribution [18]. The outdoor ambient temperature was $33^{\circ} \mathrm{C}$. Outflow boundary conditions were applied at the air outlet.

\section{SIMULATION RESULTS AND ANALYSIS}

\subsection{Simulation Results}

In order to compare the air distributions and ventilation effects of the various schemes, typical sections were selected for the different schemes. The velocity distributions in the section at a vertical height of $2 \mathrm{~m}$ (namely $z=-4.9 \mathrm{~m}$ ) and the temperature distributions in the section at a height of $5 \mathrm{~m}$ from the ground over the main transformer were analyzed and compared. The three-dimensional streamline charts for the ventilation schemes were used to analyze the advantages and disadvantages of the air distributions of the schemes. In addition, in order to analyze the ventilation effects of the various schemes, the average temperatures at heights of 0.8 $\mathrm{m}, 1.5 \mathrm{~m}$, and $2 \mathrm{~m}$ in the operating area were used as references to compare values.

The velocity distributions in the section at a vertical height of $2 \mathrm{~m}$ (namely, $\mathrm{z}=-4.9 \mathrm{~m}$ ) for the different schemes are shown in Fig. (2). Fig. (3) shows the three-dimensional streamline charts for the six ventilation schemes. Fig. (4) shows the temperature distributions in the section at a height of $5 \mathrm{~m}$ for the six ventilation schemes. Table 4 gives the values for the average temperatures at heights of $0.8 \mathrm{~m}, 1.5 \mathrm{~m}$, and $2 \mathrm{~m}$ in the operating area of the main transformer.

\subsection{Analysis of the Simulation Results}

\subsubsection{Scheme a}

As indicated by the velocity and temperature distributions for Scheme a, the jets at the air inlets carried surrounding air to the opposite side and flowed forward and backward under the guidance of the airflow passages between the front and rear radiator fins of the main transformer and the front and rear walls. Airflow formed two relatively small vortexes between the two air inlets and whirlpools of air between the two jets and the front and rear walls while forming a large airflow dead zone between the main transformer and the wall 


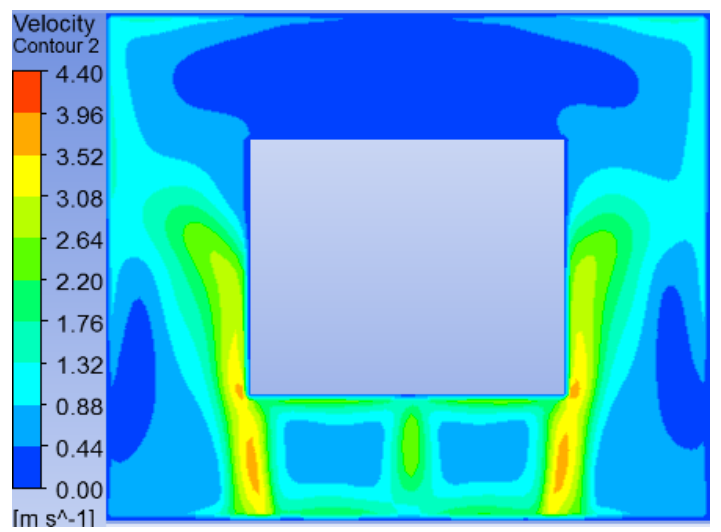

(a) The velocity field in the section at a height of $2 \mathrm{~m}$ for Scheme a

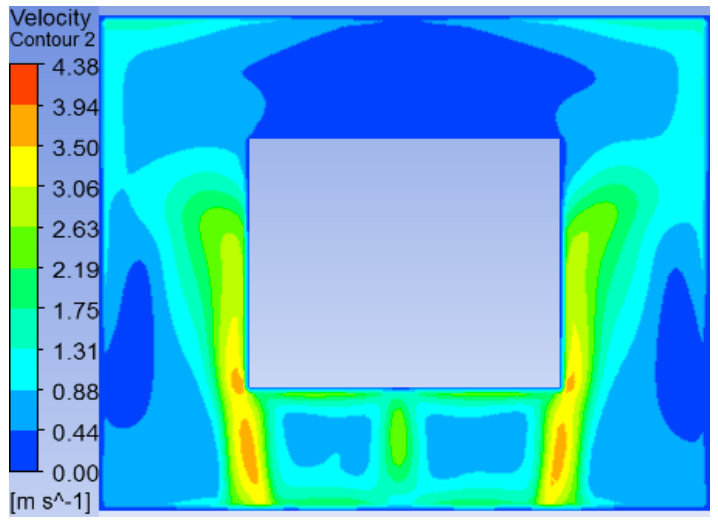

(b) The velocity field in the section at a height of $2 \mathrm{~m}$ for Scheme $\mathrm{b}$

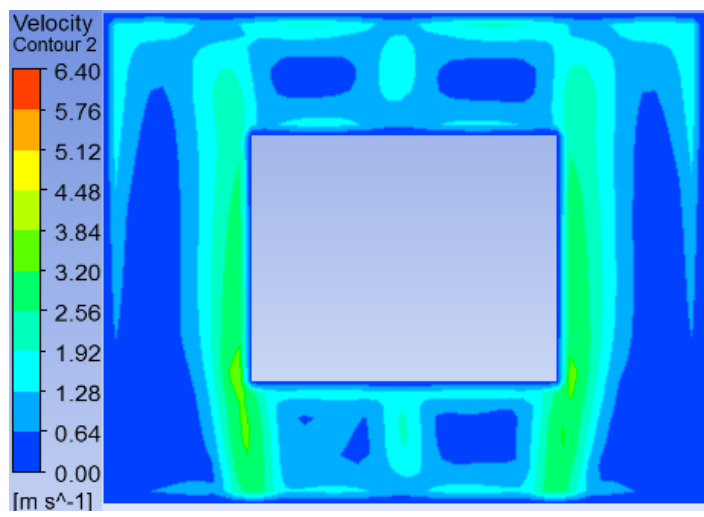

(c) The velocity field in the section at a height of $2 \mathrm{~m}$ for Scheme c

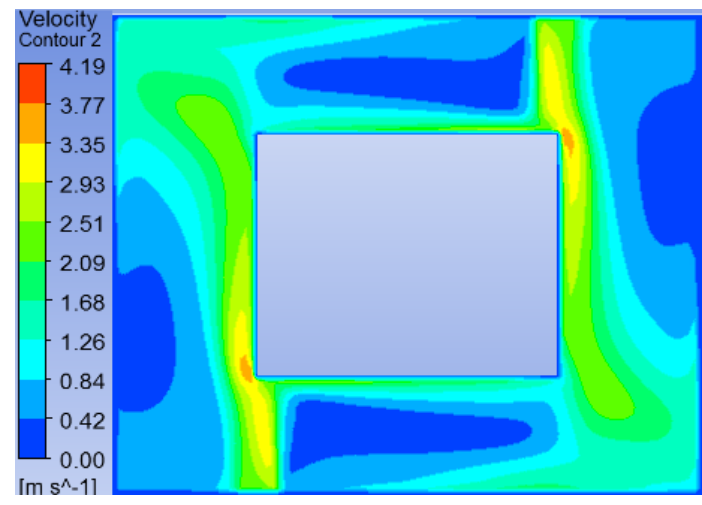

(d) The velocity field in the section at a height of $2 \mathrm{~m}$ for Scheme $\mathrm{d}$ 


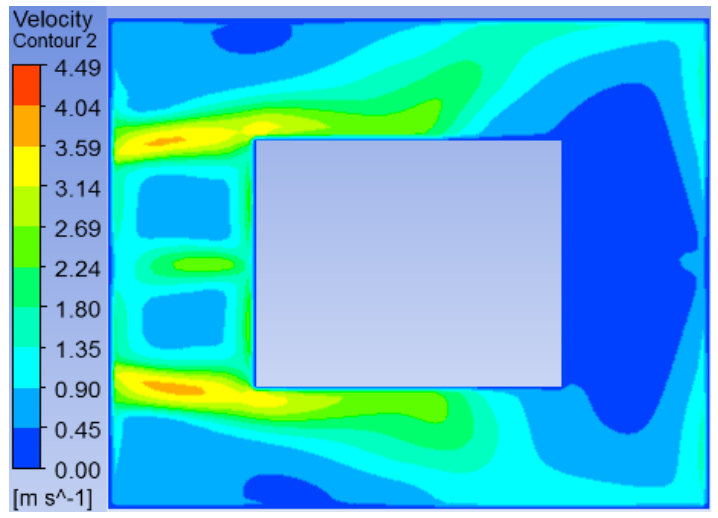

(e) The velocity field in the section at a height of $2 \mathrm{~m}$ for Scheme e

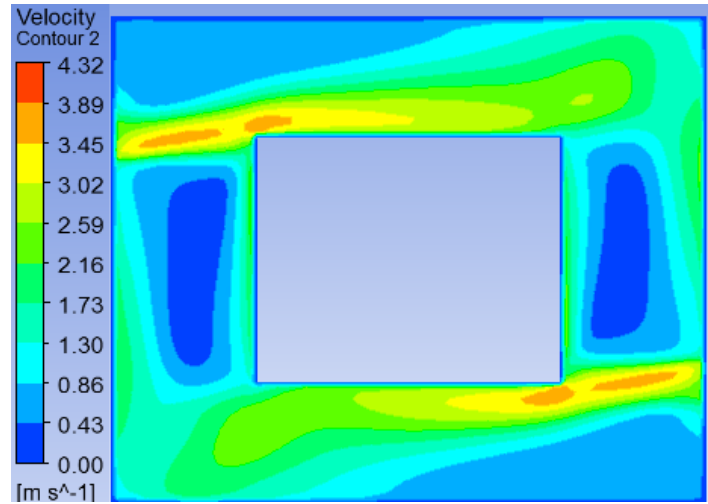

(f) The velocity field in the section at a height of $2 \mathrm{~m}$ for Scheme $\mathrm{f}$

Fig. (2). The velocity distributions in the section at a height of $2 \mathrm{~m}$ for the various ventilation schemes.

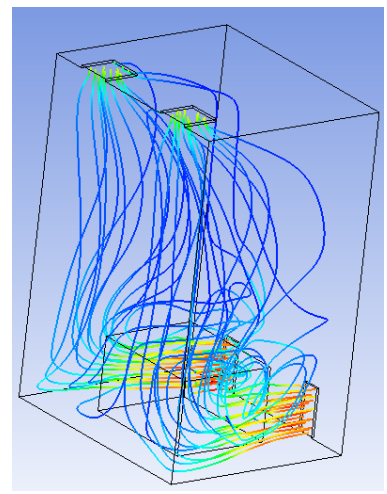

(a) Streamline chart for Scheme a

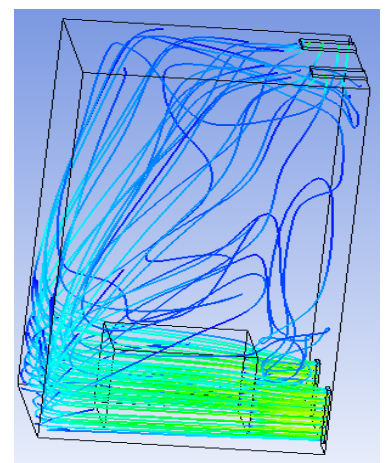

(c) Streamline chart for Scheme c

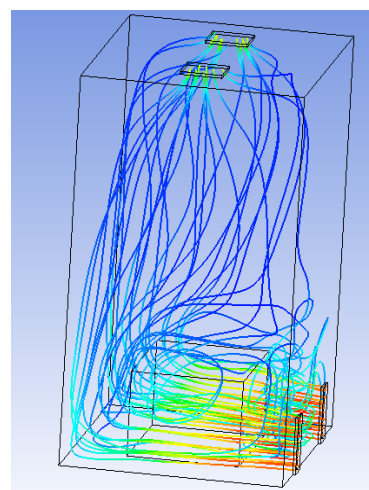

(b) Streamline chart for Scheme b

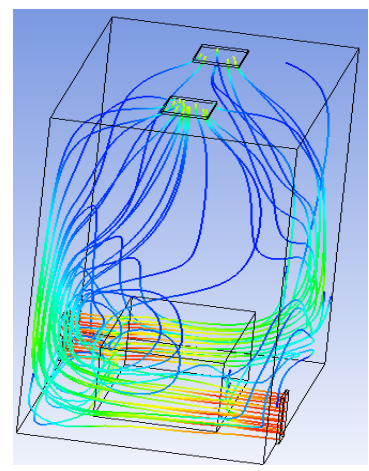

(d) Streamline chart for Scheme d

Fig. (3). Contd... 


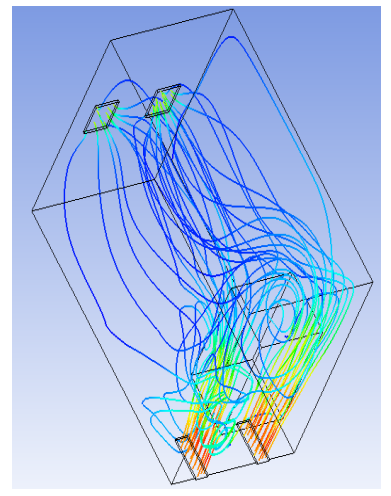

(e) Streamline chart for Scheme e

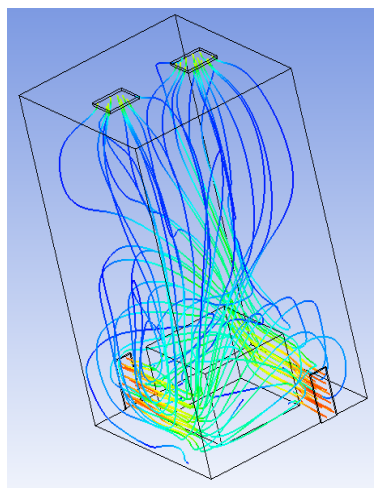

(f) Streamline chart for Scheme f

Fig. (3). The three-dimensional streamline charts for the different ventilation schemes.

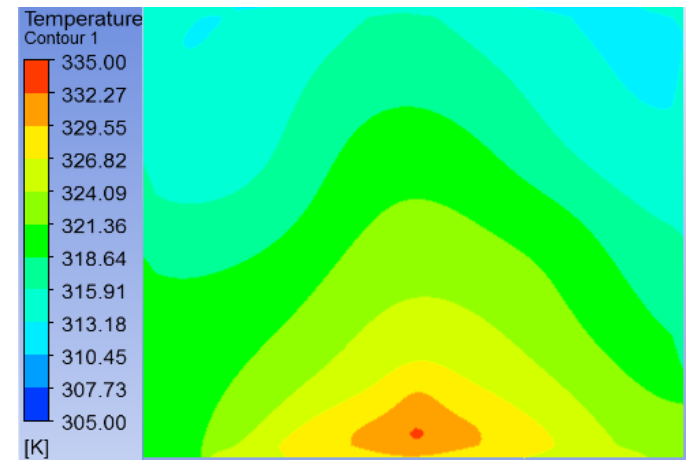

(a) The temperature field in the section at a height of $5 \mathrm{~m}$ for Scheme a

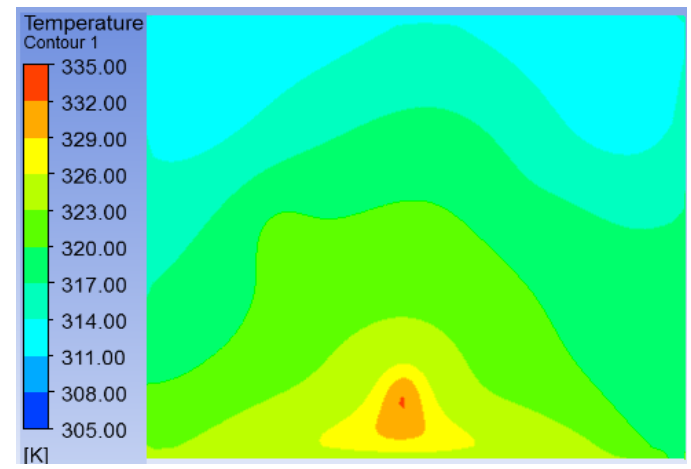

(b) The temperature field in the section at a height of $5 \mathrm{~m}$ for Scheme $\mathrm{b}$

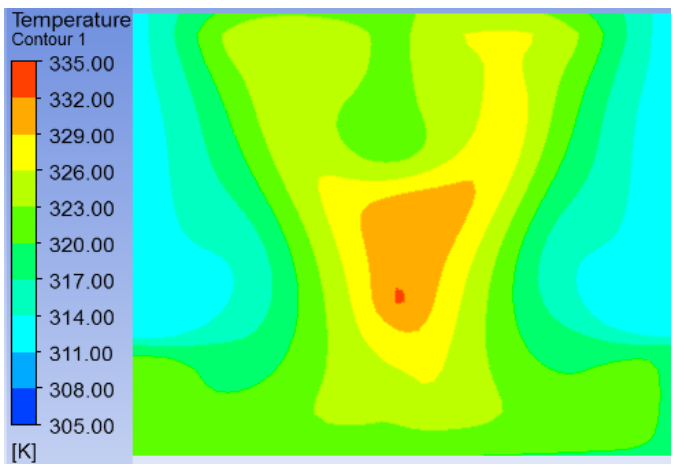

(c) The temperature field in the section at a height of $5 \mathrm{~m}$ for Scheme c

Fig. (4). Contd... 


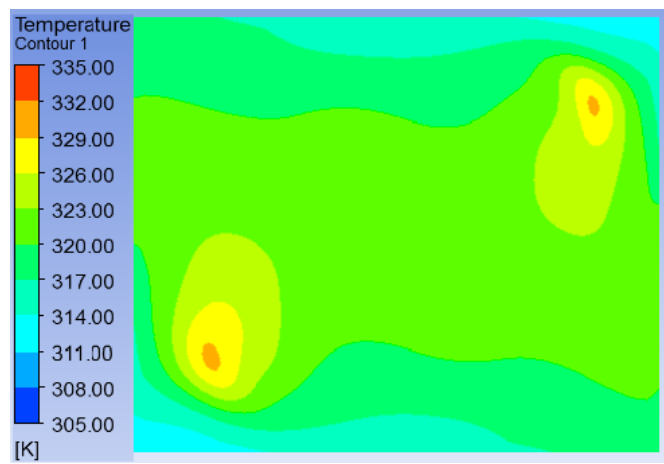

(d) The temperature field in the section at a height of $5 \mathrm{~m}$ for Scheme $\mathrm{d}$

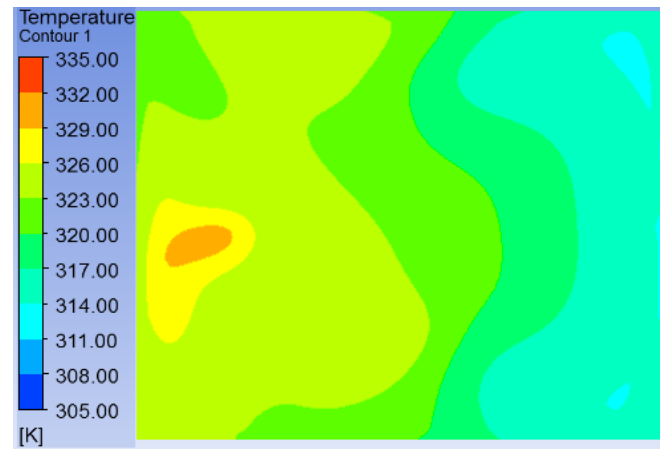

(e) The temperature field in the section at a height of $5 \mathrm{~m}$ for Scheme e

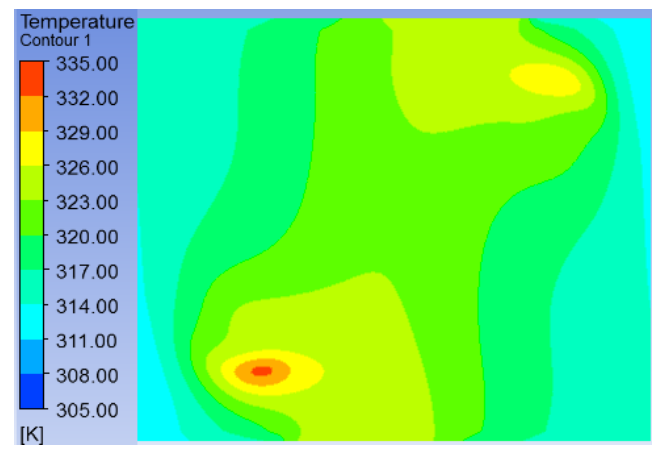

(f) The temperature field in the section at a height of $5 \mathrm{~m}$ for Scheme $\mathrm{f}$

Fig. (4). The temperature distributions in the section at a height of $5 \mathrm{~m}$ for the different ventilation schemes.

on the opposite side of the air inlets. As shown in the threedimensional streamline chart for Scheme a, air flowed straight upward through the passage from the front to the back and flowed out through the air outlets after entering the main transformer room through the air inlets. Therefore, large airflow dead zones existed in the bottom of the left side of the main transformer and above the air inlets (the right side of the main transformer). And the middle part of the air inlet side in the section at a height of $5 \mathrm{~m}$ was the highest temperature zone, indicating that Scheme a had good cooling effects on the air inlet and front and rear sides of the main transformer but had poor cooling effects on the opposite side of the air inlets and the left side of the main transformer.

\subsubsection{Scheme b}

As indicated by the velocity and temperature distributions for Scheme b, the section at a height of $2 \mathrm{~m}$ and temperature distribution for Scheme $b$ were similar to those for Scheme a. However, as shown in the three-dimensional streamline chart, because the air outlets were located in the middle, air flowed to the opposite side of the air inlets (left side) after entering the main transformer room through the air inlets on the right side and then circled backwards and flowed to the air outlets on the top. Therefore, more air flowed to the left side of the main transformer when compared to Scheme a, indicating that Scheme b had good cooling effects on the air inlet and front and rear sides 
of the main transformer and poor cooling effects on the opposite side of the air inlets and the left side of the main transformer, which, however, were better than Scheme a.

\subsubsection{Scheme c}

As indicated by the velocity and temperature distributions for Scheme c, the section at a height of $2 \mathrm{~m}$ and the temperature distribution in the section at a height of $5 \mathrm{~m}$ were similar to those for Scheme a. However, as shown in the three-dimensional streamline chart, because the air outlets were located on the same side as the air inlets, air flowed to the opposite side after entering the main transformer room through the air inlets on the right side and then circled backwards and flowed to the air outlets on the top. Therefore, more air flowed to the left side of the main transformer when compared to Scheme b, indicating that Scheme c had good cooling effects on the air inlet and front and rear sides of the main transformer. Seen from the velocity distribution, the air distribution on the air inlet side (right side) of the main transformer was similar to that on the left side, indicating that the fullness of air on the left side approximated to that on the air inlet side. Therefore, the cooling effect on the leeward side improved, which is also indicated by the temperature distribution in the section at a height of $5 \mathrm{~m}$ for Scheme c, where the highest temperature zone moved to the center, indicating that cooling on the various sides of the transformer was more even for Scheme c.

\subsubsection{Scheme d}

As indicated by the velocity and temperature distributions for Scheme d, air formed four swirling centers between the two jets and the four walls, but the swirling centers were distant from the walls of the main transformer. Therefore, this scheme had few dead zones on the four walls of the main transformer as well as a good cooling effect. The threedimensional streamline chart indicates that the fullness of air surrounding the main transformer was good for this scheme, thus facilitating ventilation. In addition, as indicated by the temperature distribution in the section at a height of $5 \mathrm{~m}$ over the main transformer, small symmetrical high-temperature zones formed at a distance of $2 \mathrm{~m}$ away from the corresponding walls above the air inlets, showing that the air distribution for Scheme $\mathrm{d}$ was characterized by the staggered arrangement of the air inlets, the good fullness of air, the great distance of the air dead zones from the main transformer, and the even and effective cooling effects on the walls.

\subsubsection{Scheme e}

As indicated by the velocity distribution in the section at a height of $2 \mathrm{~m}$ and the temperature distribution in the section at a height of $5 \mathrm{~m}$ for Scheme e, the air inlets were arranged on the same side, which was similar to that for Scheme b. Therefore, the two schemes had similar air distribution characteristics and cooling effects. However, the airflow blocking section of the main transformer (the section of the front in the airflow direction) for Scheme e was smaller than that for Scheme b. Therefore, the simulation results and distribution effects for Scheme e were better than those for Scheme b. However, the transformer was simplified to a cuboid for simulation. In practical engineering, the direction of the radiating fin should be consistent with the airflow direction, which will yield the smallest airflow blocking section and produce the best cooling effects.

\subsubsection{Scheme $f$}

As indicated by the velocity distribution in the section at a height of $2 \mathrm{~m}$ and the temperature distribution in the section at a height of $5 \mathrm{~m}$ for Scheme $\mathrm{f}$, the air inlets were staggered on the different sides of the main transformer, which was similar to that for Scheme d. Therefore, the two schemes had similar air distribution characteristics and cooling effects. However, the airflow blocking section of the main transformer (the section of the front) for Scheme $f$ was smaller than that for Scheme d. Therefore, the simulation results and distribution effects were better than those for Scheme $b$ and were characterized by good fullness of air, the great distance of airflow dead zones from the main transformer, and the even and effective cooling effects on the various walls.

As shown by the above analysis of the velocity and temperature distributions and the numerical simulation results of temperature in the operating area for the various schemes, Schemes c, d, and f had low operating temperatures while the operating area temperatures for Schemes $a, b$, and e were $3 \sim 4^{\circ} \mathrm{C}$ higher than those for the above three schemes, thereby validating the above analysis results from another aspect.

\section{CONCLUSION AND SUGGESTIONS}

The following conclusions were drawn from the above analysis:

1) The ventilation effects for Schemes $c, d$, and $f$ were good, while the ventilation effects for Schemes a, b, and e were poor.

2) Under the condition of the convenient arrangement of the architectural structure of main transformer rooms, air inlets are advised to be staggered on opposite sides, which can increase the effective and even cooling of the main transformer and reduce air dead zones.

3) If air inlets are only allowed to be arranged on the same side in practical buildings, air outlets should be arranged on the same side as the air inlets in order to increase the distance over which air circles and the fullness of air in the main transformer room and improve the cooling effects of air on the leeward side of the main transformer.

\section{CONFLICT OF INTEREST}

The authors confirm that this article content has no conflict of interest.

\section{ACKNOWLEDGEMENTS}

This work was supported by National Natural Science Foundation of China (61262048, 51167005) and Technological Supporting Project Foundation of State Grid Company (521820130018). 


\section{REFERENCES}

[1] G. Zhang, "Developing trends of substation in big cities," China Electric Power Education, vol.12, pp. 90-91, 2011.

[2] L. Jin, "Research on ventilation and noise reduction of main transformer chamber in urban indoor substation," Electricity Supply and Consumption, vol. 27, no. 4, pp. 39-41, 2010.

[3] W. Han, and L. Gan, "220 kV Ventilation system design for indoor 220 kV substations," Heat Ventilation \& Air Condition, vol. 41, no. 5, pp. 47-49, 2011.

[4] S. Guo, W. Huang, and L. Xue, "Ventilation mode of indoor substation based on integrated environmental control technology," Journal of Beijing Jiaotong University, vol. 37, no. 3, pp. 19-26, 2013.

[5] L. Shu, W. Hu, M. Chen, and Z. Yang, "Research on hybrid ventilation mode of indoor substation," Building Science, vol. 28, no. 2, pp. 84-87, 2012

[6] Z. Hua, R. Min, G. He, G. Neng, and Y. Bu, 35 110kv Substation Design (GB50059-92), China Planning Press, China, 1993.

[7] Y. Jiang, and Q. Chen, "Study of natural ventilation in building by large eddy simulation," Journal of Wind Engineering and Industrial Aerodynamics, vol. 89, no. 13, pp. 1155-1178, 2001.

[8] L. Xu, G. Wang, J. Ding, and J. Chen, "The CFD numerical simulation on ventilation of indoor transformer substation," Hydromechatronics Engineering, vol. 41, no.18, pp. 141-144, 2013.

[9] X. Wan, "Numerical Simulation of Natural Ventilation in Industrial Plant with Heat Source," Maters Dissertation, Donghua University, 2008.

[10] K. Shu, Y. Huang, and S. Zhang, "Reasonable layout and numerical simulation of compound ventilation mode in power transformer room," Building Energy Efficiency, vol. 38, no. 1, pp. 34-38, 2010.
[11] C. R. Juan, M. Beiza, G. Jon, A. Rivas, A. Raúl, G. S. Larraona, and I. de Miguel, "Numerical modeling of the natural ventilation of underground transformer substations," Applied Thermal Engineering, vol. 51, no. 1-2, pp. 852-863, 2013.

[12] X. Yang, G. Liu, and Q. Yang, "Numerical simulation on cooling and ventilation of transformer room in underground transformer substation," Building Energy \& Environment, vol. 30, no. 1, pp. 94 96, 2011.

[13] Q. Huang, X. Liu, and L. Chen, "Study on air distribution in transformer plants of substations of metro stations: case study on a station of tianjin metro," Tunnel Construction, vol. 30, no. 4, pp. 396401, 2010.

[14] C. R. Juan, M. Beiza, G. Jon, A. Rivas, R. Antón, G. S. Larraona, and I. de Miguel, "Numerical modeling of the natural ventilation of underground transformer substations," Applied Thermal Engineering, vol. 51, no. 1-2, pp. 852-863, 2013.

[15] C. Teodosiu, "Experimental and numerical prediction of indoor air quality," In: Proceedings of Roomwent Reading, UK, 2000.

[16] T. V. Hooff, and B. Blocken, "Full-scale measurements of indoor environmental conditions and natural ventilation in a large semienclosed stadium: Possibilities and limitations for CFD validation,' Journal of Wind Engineering and Industrial Aerodynamics, vol. 104-106, pp. 330-341, 2012.

[17] R. Ramponi, and B. Blocken, "CFD simulation of cross-ventilation flow for different isolated building configurations: Validation with wind tunnel measurements and analysis of physical and numerical diffusion effects," Journal of Wind Engineering and Industrial Aerodynamics, vol. 104-106, pp. 408-418, 2012.

[18] B. Zhao, X. Li, and Q. Yan, "Numerical simulation of the air jet from a register," Heat Ventilation \& Air Condition, vol. 31, no. 6, pp. 86-89, 2011.

(C) Huijuan et al.; Licensee Bentham Open.

This is an open access article licensed under the terms of the Creative Commons Attribution Non-Commercial License (http://creativecommons.org/licenses/bync/4.0/) which permits unrestricted, non-commercial use, distribution and reproduction in any medium, provided the work is properly cited. 